\title{
Meningkatan keaktifan dan hasil belajar IPS melalui model jigsaw pada materi atmosfer dan hidorsfer
}

\section{Agus Suprasetyo $^{1}$}

Diterima 2 Mei 2019, Dipublikasikan 31 Oktober 2019

CJTP2IPS (2019)

\begin{abstract}
Seventy-five percent of Social Studies learning outcomes in atmospheric material and hydrosphere students at Pesanggrahan 2 Batu One Roof Junior High School, scored below the average KKM. That encourages teachers to implement improvements in social studies learning in the classroom. Improved learning designed into classroom action research activities. The learning method used in learning classroom action is a type of jigsaw cooperative learning. Data collection uses observation techniques using a collection of observation sheets. How in the first cycle, through a type of jigsaw cooperative learning model, student learning outcomes in solving social studies questions for junior high school class VII can improved. Students who completed the study in the first cycle of classroom action research, $30 \%$, with an average value of 48, while in the first cycle, $78 \%$ of students completed the study with an average value of 71. In cycle II, students were active in studying social studies material on atmospheric material, and the VII grade junior high school hydrosphere was successful. Cycle I classroom action research-active students only 46\%. While after completing the second cycle of action the percentage of activity reached $82 \%$. The results of this study prove the role of giving more to students in learning considering the improvement in learning outcomes.
\end{abstract}

\section{Keywords}

Cooperative learning, Jigsaw, Classroom Action Research

\section{PENDAHULUAN}

Kegiatan belajar-mengajar tidak bisa lepas dari keberadaan guru. Tanpa adanya guru pembelajaran akan sulit dilakukan, apalagi dalam rangka pelaksanaan pendidikan formal, guru menjadi pihak yang sangat vital. Guru memiliki peran yang paling aktif dalam pelaksanaan pendidikan demi mencapai tujuan pendidikan yang hendak dicapai. Siswa juga akan kesulitan dalam belajar atau pun menerima materi tanpa keberadaan seorang guru atau pendidik, hanya mengandalkan sumber belajar dan media pembelajaran saja akan sulit dalam penguasaan materi tanpa adanya bimbingan guru. Kewajiban seorang guru dalam pembelajaran adalah merencanakan pembelajaran, melaksanakan proses pembelajaran, hingga melakukan evaluasi pembelajaran yang telah dilakukan.

Marpaung (2003) mengungkapkan pada umumnya proses pembelajaran masih di dominasi oleh paradigma mengajar yang memiliki ciri-ciri sebagai berikut: (a) guru aktif menyampaikan informasi dan siswa pasif menerima: (b) siswa "dipaksa" mempelajari apa yang diajarkan oleh guru dengan menerapkan jenis "hukuman" bukan dengan menumbuhkan kesadaran akan makna belajar, (c) pembelajaran berfokus (berorientasi) pada guru bukan pada siswa (d)

1 SMP Negeri Satu Atap Pesanggrahan 2 Batu agus_prasetyo@gmail.com

Jurnal Teori dan Praksis Pembelajaran IPS Volume 4, No.2, 2019, ISSN 2503-5307 
ketergantungan siswa pada guru cukup besar, independensi berpikir pada siswa kurang dikembangkan (f) pemahaman mereka mengenai materi yang dipelajari di periksa melalui tes obyektif, (g) kesempatan bagi siswa untuk melakukan refleksi dan negosiasi melalui interaksi antara siswa dengan siswa dan antara siswa dengan guru kurang dikembangkan dan, (h) pemahaman yang di capai siswa cenderung pada pemahaman instrumental bukan pada pemahaman relasional. Dari paradigma tersebut masih banyak guru yang menggunakannya, disebabkan oleh anggapan bahwa paradigma tersebut sebagai salah satu alternatif. Metode konvensional seperti yang telah disampaikan di atas sebagian besar tidak mempergunakan media sebagai sarana untuk meningkatkan kemampuan.

Melihat kenyataan yang demikian maka seorang guru hendaknya senantiasa memberikan motivasi kepada siswa agar siswa tidak merasa bosan dan malas belajar, terutama pada mata pelajaran IPS yang berakibat menurunnya prestasi siswa. Aktivitas belajar di kelas berawal dari adanya interaksi antara guru dan siswa. Interaksi yang terjadi selama proses belajar tersebut dipengaruhi oleh lingkungannya, yang terdiri atas murid, guru, petugas perpustakaan, kepala sekolah, bahan/materi pelajaran, dan berbagai sumber belajar lainnya dan fasilitas (Arsyad, 2010).

Berdasarkan pengamatan penulis, prestasi belajar mata pelajaran IPS siswa SMPN Satu Atap Pesanggrahan 2 Batu, pada semester II tahun ajaran 2016/2017 rendah yaitu75\% siswa yang mendapat nilai di bawah rata-rata kriteria ketuntasan minimal (KKM) dari KKM yang telah di tetapkan yaitu 75. Banyak faktor penyebab menurunnya prestasi belajar siswa-siswi yang SMPN Satu Atap Pesanggrahan 2 Batu, menurut penulis kurang berminat mengikuti pembelajaran, kurang motivasi, metode pembelajaran yang masih monoton, kurang variatif, siswa kurang aktif, kurang kreatif yang ditambah dengan kurangnya minat baca siswa terhadap buku.

Berdasarkan uraian permasalahan tersebut di atas, salah satu upaya yang digunakan guru dalam meningkatkan prestasi siswa adalah dengan cara menerapkan model pembelajaran kooperatif tipe jigsaw. Pembelajaran jigsaw lebih menekankan pada kerja sama kelompok dan keaktifan dari setiap anggota, yang mana tiap anggota di haruskan untuk mengerjakan tugas yang dibebankan kepada yang bersangkutan untuk di bawa ke dalam anggota kelompok tim ahli sehingga dapat mengurangi kejenuhan dalam kelompok. Studi empiris menunjukkan bahwa model ini mampu untuk untuk meningkatkan aktivitas dan hasil belajar (Miaz, 2012; Adimassana dan Rusmawan, 2017; Mujiyono, Noviana dan Jaino, 2017; Rismawati, Rustono dan Nugraha, 2017). Maka dari itu asumsi dari solusi untuk permasalahan pembelajaran yang terjadi adalah menggunakan model jigsaw..

\section{METODE}

Penelitian ini dirancang dalam penelitian tindakan kelas (PTK). Harapannya adalah untuk meningkatkan prestasi siswa kelas VII SMP Negeri Satu Atap Pesanggrahan 2 Batu, pada mata pelajaran IPS. PTK ini juga dilakukan untuk memperbaiki strategi pembelajaran yang telah dilakukan oleh guru sebelumnya. Prosedur pelaksanaan PTK ada empat langkah, yakni: 1) Perencanaan (planning), 2) Pelaksanaan tindakan (acting), 3) Pengamatan (observing), dan 4. Refleksi (reflecting). Langkah berikutnya ialah siklus baru dengan perencanaan ulang. Model PTK yang diterapkan ialah model PTK dari Kemmis dan Taggart. 


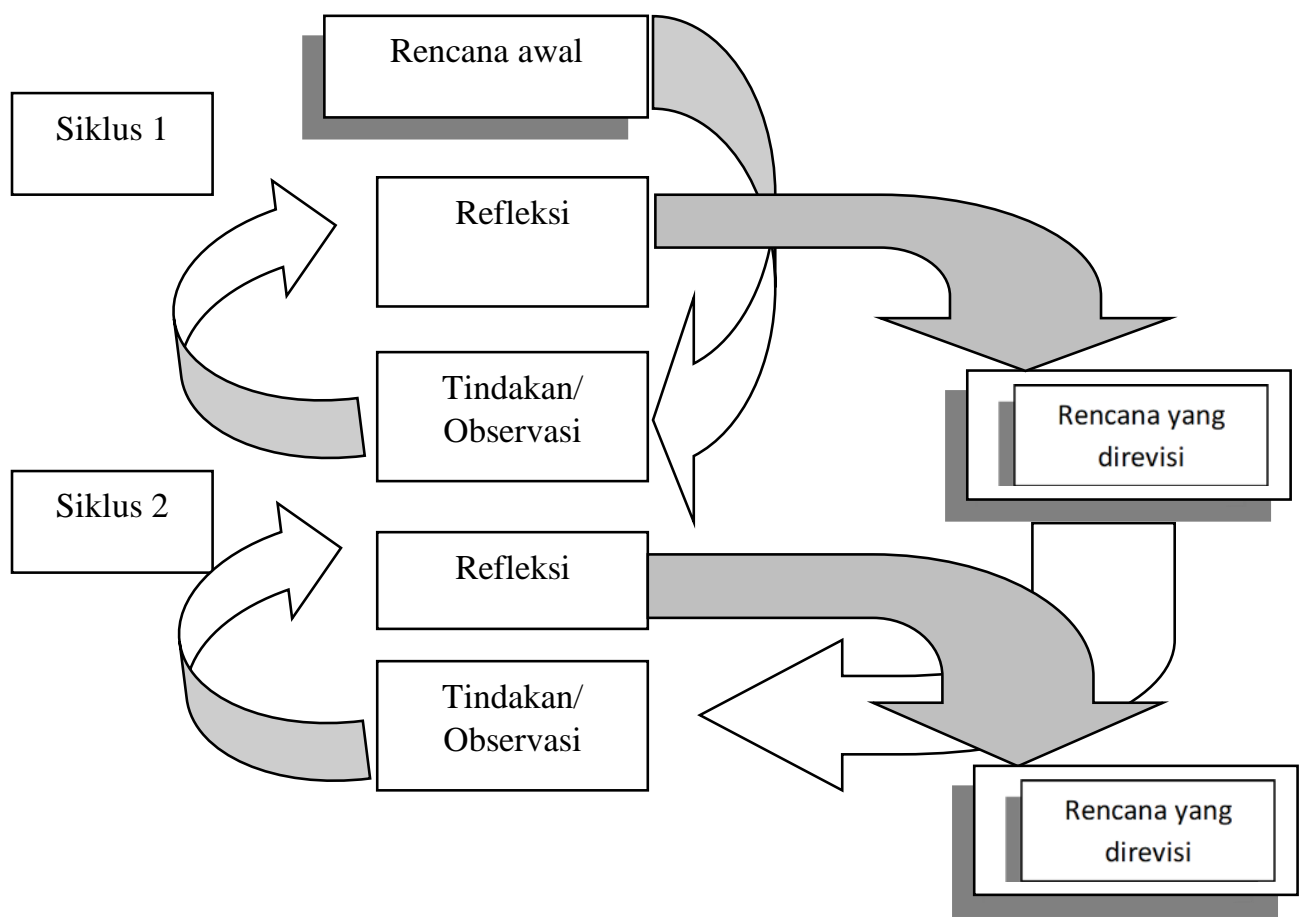

Gambar 1. Siklus PTK model Spiral Kemmis Taggart (dalam Arikunto, 2006)

Penelitian ini bertempat di SMPN Satu Atap Pesanggrahan 2 Batu. Penelitian ini dimulai pada bulan Maret semester ganjil tahun pelajaran 2016-2017. Subyek penelitian adalah siswa siswi kelas VII. Teknik pengumpulan data dengan cara observasi menggunakan instrumen lembar observasi.

Seorang siswa telah tuntas belajar bila telah mencapai skor 70, dan kelas disebut tuntas belajar bila di kelas tersebut terdapat $70 \%$ yang telah mencapai daya serap lebih dari atau sama dengan $70 \%$. Untuk menghitung persentase ketuntasan belajar digunakan rumus sebagai berikut.

$$
\mathrm{PK}=\frac{\sum \text { Siswa yang tuntas belajar }}{\sum \text { Siswa }} \times 100 \%
$$

Untuk melihat keaktifan siswa dalam penerapan model jigsaw digunakan rumus penghitungan sebagai berikut.

$$
\mathrm{PA}=\frac{\sum \text { siswa yang aktif }}{\sum \text { siswa seluruhnya }} \times 100 \%
$$

\section{HASIL DAN PEMBAHASAN}

Siklus I dilakukan pembelajaran dengan materi atmosfer melalui model jigsaw. Hasilnya menunjukkan ada beberapa siswa yang masih bingung terhadap model ini. Kondisi tersebut karena faktor guru kurang melakukan sosialisasi. Oleh karena itu agar kegiatan belajar mengajar berjalan efektif, guru selain menjelaskan juga mendemonstrasikan model pembelajaran ini dengan jelas. Selain itu ada beberapa kelompok yang pasif dan juga ada kelompok yang aktif dalam menyelesaikan masalah, dikarenakan pembagian kelompok 
heterogen. Dampaknya adalah ada kelompok yang kebetulan anggotanya kurang aktif atau mengganggu yang berakibat mengganggu kelompok lain. Sedangkan ada kelompok yang aktif, sibuk bekerja sama karena kebetulan anggota kelompoknya semua pandai. Oleh karena itu dalam pembentukan kelompok seharusnya memperhatikan penyebaran kemampuan sehingga semua kelompok tampak hidup (Purnomo dan Purwasih, 2019). Beberapa orang siswa dalam suatu kelompok yang masih takut dan kurang berani maju ke depan mempresentasikan hasil pekerjaannya dikarenakan kurang percaya diri bahwa hasil temuannya adalah benar.

Secara garis besar pelaksanaan siklus I berlangsung cukup baik dan kondusif, walaupun hasil belajar siswa baru mencapai rata-rata 48 dan baru 30\% siswa dari 21 siswa yang mencapai nilai minimal dari 70 sehingga ketuntasan yang dicapai baru $30 \%$, berarti ada 19 siswa yang belum tuntas, ini berarti pembelajaran yang dilaksanakan kurang optimal dan perlu perbaikan pada siklus II.

Proses belajar mengajar dengan model pembelajaran kooperatif tipe jigsaw, ini berjalan lancar, semua siswa telah memahami dan berjalan sendiri tanpa harus diperintah, kondisi kelas sudah dipersiapkan sebelumnya. Instruksi atau petunjuk belajar yang jelas akan memudahkan siswa dalam memahami maksud dari kegiatan belajar yang didesain oleh guru(Ratnawati dkk., 2017; Purnomo dan Purwasih, 2019).

Suasana kelompok dalam pembelajaran sudah aktif, sebagian besar anggota kelompok kelihatan aktif, suasana kelas menjadi hidup diwarnai dengan diskusi, tanya jawab dari anggota kelompok, ini dikarenakan tingkat kecerdasan dan sifat atau watak anak telah merata pada semua kelompok, suasana kelompok seimbang dan tidak lagi terlihat kelompok yang cerewet dan pendiam karena telah disebar merata. Pembagian kelompok yang efektif dan homogen menjadi kunci dari pelaksanaan pembelajaran kooperatif (Soraya Mei dan Purnomo, 2019).

Sebagian besar siswa dalam suatu kelompok kepercayaan terhadap diri sendiri sudah tumbuh, sehingga mereka tidak malu bahkan berlomba-lomba untuk tampil di depan kelas untuk mempresentasikan hasil temuannya, dikarenakan kesadaran siswa dan motivasi guru, sehingga tumbuh rasa percaya diri pada setiap individu selain itu Sebagian besar siswa sudah benar dalam menjawab soal-soal bab Hidrosfer, walaupun masih ada siswa yang masih menjawab salah, karena keterlambatan berpikir, sehingga penjelasan guru kurang dipahami, guru sudah memperhatikan dan membimbing siswa yang terlambat berpikir, tapi memang keterbatasan waktu, sehingga perlu waktu khusus untuk memberi bimbingan kepada siswa tersebut sehingga dapat mengikuti pelajaran selanjutnya.

Pelaksanaan siklus II berlangsung dengan baik dan kondusif, serta aktivitas belajar siswa meningkat. Hasil belajar siswa telah mencapai rata-rata 71 dan secara klasikal ketuntasan belajar siswa telah mencapai $78 \%$ sehingga masih $22 \%$ yang belum tuntas atau masih ada 6 siswa dari 21 siswa yang mendapat nilai kurang dari 70 dan ini sulit dihindari karena faktor keterbatasan berpikir, namun dapat dikatakan pelaksanaan siklus II ini berhasil, karena ada peningkatan kemampuan siswa dalam menyelesaikan soal baik soal LKS (lembar kerja siswa) maupun soal tes formatif, sehingga peneliti dapat mengatakan siklus II telah berhasil dengan baik.

Keberhasilan untuk mengatasi permasalahan pembelajaran menggunakan model jigsaw memberikan penguawan wawasan bahwa model ini sesuai untuk diterapkan pada materi dengan karakter yang abstrak. Materi atmosfer dan hidrosfer meski ada pada lingkungan sekitar siswa, tidak memiliki bentuk yang nyata karena cakupannya yang sangat luas (Purnomo, 2016). 
Jigsaw memberikan pengalaman belajar mandiri kepada siswa untuk membangun materinya yang kemudian di konfirmasikan pada rekan sejawat. Tahap konfirmasi ke rekan sejawat mampu membangun kepercayaan diri mereka terhadap pengetahuan yang sudah didapatkan (Buana dan Purnomo, 2019).

\section{SIMPULAN}

Berdasarkan pelaksanaan penelitian tindakan kelas di kelas VII SMP Negeri Satu Atap Pesanggrahan 2 Bat $u$ dapat disimpulkan sebagai berikut; (1) melalui model pembelajaran kooperative tipe jigsaw, hasil belajar siswa dalam meyelesaikan soal-soal IPS bagi siswa kelas VII SMP Negeri Satu Atap Pesanggrahan 2 Batu tahun pembelajaran 2016 - 2017 dapat ditingkatkan. Siswa yang tuntas belajar pada penelitian tindakan kelas siklus I, 30\%, dengan nilai rata-rata 48, sedangkan pada siklus I, 78\% siswa tuntas belajar dengan nilai rata-rata 71, dan (2) melalui pelaksanaan model pembelajaran kooperatif tipe jigsaw, keaktifan siswa dalam menyelesaikan soal-soal Atmosfer dan Hidrosfer bagi siswa kelas VII SMP Negeri Satu Atap Pesanggrahan 2 Batu tahun pembelajaran 2016-2017 dapat ditingkatkan. Penelitian tindakan kelas siklus I siswa aktif hanya $46 \%$. Sedangkan setelah penelitian tindakan kelas siklus II persentase keaktifan mencapai $82 \%$.

Hasil riset ini menunjukkan bahwa memberikan peran lebih kepada siswa dalam pembelajaran berdampak pada peningkatan hasil belajar. Namun karena pada riset ini hanya desainpenelitian tindakan, kedalam kajian untuk efektifitas model menjadi kurang. Oleh karena itu rekomendasi untuk riset selanjutnya adalah untuk melakukan kajian eksperimen model jigsaw pada materi yang lebih beragam.

\section{DAFTAR PUSTAKA}

Adimassana and Rusmawan (2017) Efektivitas penerapan model pembelajaran kooperatif tipe jigsaw pada mata pelajaran IPS SD.

Arikunto, S. 2006. Metode Penelitian Kualitatif. Jakarta: Bumi Aksara

Arsyad, 2010, Media Pembelajaran. Jakarta, PT Grafindo Persada.

Buana, Y. I. K. and Purnomo, A. (2019) 'Meningkatkan motivasi belajar siswa pada materi perdagangan internasional melalui model Make A Match di kelas IX C SMP Lab UM', Jurnal Teori dan Praksis Pembelajaran IPS. State University of Malang (UM), 4(1), pp. 16. doi: 10.17977/um022v4i12019p001.

Marpaung, Y. 2003. Perubahan Paradigma Pembelajaran Matematika di Sekolah. Makalah disajikan dalam Seminar Nasional Pendidikan Matematika di Universitas Sanata Darma. Tanggal 27-28 Maret 2003. Yogyakarta: Universitas Sanata Darma.

Miaz, Y. (2012) Pembelajaran kooperatif tipe jigsaw untuk meningkatkan aktivitas dan hasil belajar IPS SISWA SD | Miaz | Sekolah Dasar : Kajian Teori dan Praktik Pendidikan, Sekolah Dasar : Kajian Teori dan Praktik Pendidikan. Available at: http://journal.um.ac.id/index.php/jurnal-sekolah-dasar/article/view/3560 (Accessed: 31 October 2019).

Mujiyono, Noviana and Jaino (2017) Keefektifan Model Jigsaw Terhadap Hasil Belajar Ips Siswa Kelas IV 120 Noviana. Jurnal Kreatif Februari 2017 EST.

Purnomo, A. (2016) Geografi Fisik. Edited by K. N. Nugrahini. Yogyakarta: Ombak. 
Purnomo, A. and Purwasih, J. H. G. (2019) 'Build Student Knowledge about Natural Resources and Hazard Potential Through Field Social Studies Laboratory Product', in. Atlantis Press. doi: 10.2991/icskse-18.2019.36.

Ratnawati, N. et al. (2017) 'Pengembangan Buku Pedoman Lab Alam Fakultas Ilmu Sosial Untuk Siswa SMP', Jurnal Teori dan Praksis Pembelajaran IPS. State University of Malang (UM), 2(2), pp. 61-65. doi: 10.17977/um022v2i22017p061.

Rismawati, R., Rustono and Nugraha, A. (2017) Pengaruh Penggunaan Model Pembelajaran Kooperatif Tipe Jigsaw terhadap Hasil Belajar IPS Siswa Kelas IV di Sekolah Dasar| Rismawati | PEDADIDAKTIKA: Jurnal Ilmiah Pendidikan Guru Sekolah Dasar, PEDADIDAKTIKA: Jurnal Ilmiah Pendidikan Guru Sekolah Dasar. Available at: https://ejournal.upi.edu/index.php/pedadidaktika/article/view/7425 (Accessed: 31 October 2019).

Soraya Mei, L. and Purnomo, A. (2019) 'Membangun empati siswa melalui bermain peran pada materi konflik sosial kelas VIII C SMP Lab UM', Jurnal Teori dan Praksis Pembelajaran IPS. State University of Malang (UM), 4(1), pp. 7-14. doi: 10.17977/um022v4i12019p007. 